\title{
Educational Perspective of the Balkan Medical Journal
}

In addition to independent, impartial and active sharing of scientific information with the whole world, the mission of the Balkan Medical Journal is to train the actors taking part in this process. This responsibility was significantly defined and openly announced in the policy of our journal. Researchers, authors, reviewers and editors are considered as our target group. Our training strategy was created to be executed through face-to-face interviews with such people as much as is possible. We strive to congregate researchers, authors, reviewers and editors in one timeline in order to share knowledge and pursue innovation. Moreover, we also intend to contribute to more feasible, effective and ethical execution of scientific activity, innovations in which fly with blazing speed in Turkey, the Balkans and the whole world. This article will explore the activities we plan to offer for our target audience for the Balkan Medical Journal.

\section{Training of Researchers}

It is well known that the process prior to drafting an article consists of projecting and implementation. Viewed from this angle, an article that is sent to a scientific journal essentially has its foundations laid in the design process. Healthy design and execution of a scientific project from the very beginning will ensure the following article provides significant contributions to the scientific literature. Therefore, we believe that the researchers must initially receive training on project design. As the board members of the Balkan Medical Journal, we take part in two individual practices, nationally and internationally, towards this goal:

a) National Scale: Our editorial board plans to provide training on project design to researchers in the Thrace region. This training will be conducted in the Turkish language under the auspices of Trakya University, Faculty of Medicine, utilizing support funds from TÜBITAK (The Scientific and Technological Research Council of Turkey). It will be announced on Trakya University and Balkan Medical Journal's respective websites. These trainings will be executed by three trainers from the editorial board. In this 2-2.5-day training, how to execute a scientific project will be explained and the basic principles of project designing will be discussed. The group of participants, consisting of 20 persons, will initially discuss project design, followed either by tabling and evaluating a rejected TÜBITAK project or designing a new TÜBITAK project. Further meetings of a similar nature will be planned as per demand.
As the editors of Balkan Medical Journal, one of the issues we consider most is the publication of articles registered to one of the Clinical Trials Registration systems approved by the International Committee of Medical Editors. We strive at every opportunity to explain the importance and influence of this system to researchers and authors. We also continue to work towards establishing a national Clinical Trace Registration, which is currently unavailable in Turkey.

b) International Scale: What all journals of biomedicine need first and foremost is to publish high-quality, genuine articles. The rule in the very foundation is to finalize a research project with a strong hypothesis and proper planning. This need has driven three journals worldwide to unite to create the International Scientific Summer School (ISSS), an initiative begun in 2006 by the Journal of Electrocardiology, Croatian Medical Journal and The Anatolian Journal of Cardiology. ISSS aims to develop skills to carry out research projects through a practical problem-based approach and to establish enjoyable cross-disciplinary, cross-cultural collaboration between young and promising scientists. ISSS activities were executed 10 times in total during the past seven years, in Poland, Russia, Romania, Slovakia and Turkey. The ISSS faculty has trained around 200 young academicians from Europe, Africa, America, the Balkans and Turkey in the design of a scientific project. Balkan Medical Journal was represented for the first time in the ISSS event held in 2010 at the TÜBITAK facility in Gebze, Turkey. The latest event supported by the Balkan Medical Journal was held in June 2013 in Poland (Figure 1).

With a decree in 2013, the ISSS has added more journals to the three founding journals in the process. Therefore, Balkan Medical Journal has become a member of the ISSS initiative, which we have announced to our readers on our website. Furthermore, Hippokratia, Monitor of Medicine of Slovak Medical Society, Lietuvos Bendrosios Praktikos Gydytojas (Lithuanian Family Doctor) and MEDICINA have also been included. In accordance with the ISSS rules, a statement by the ISSS collaboration group will be published in this issue of our journal.

Through our interviews as Balkan Medical Journal, we received the necessary permits to uphold the organization of this event in 2014. We are planning to hold the ISSS in Turkey next year, in early June. We thus hope to provide an important training service on project design to young academics in the Balkans. 


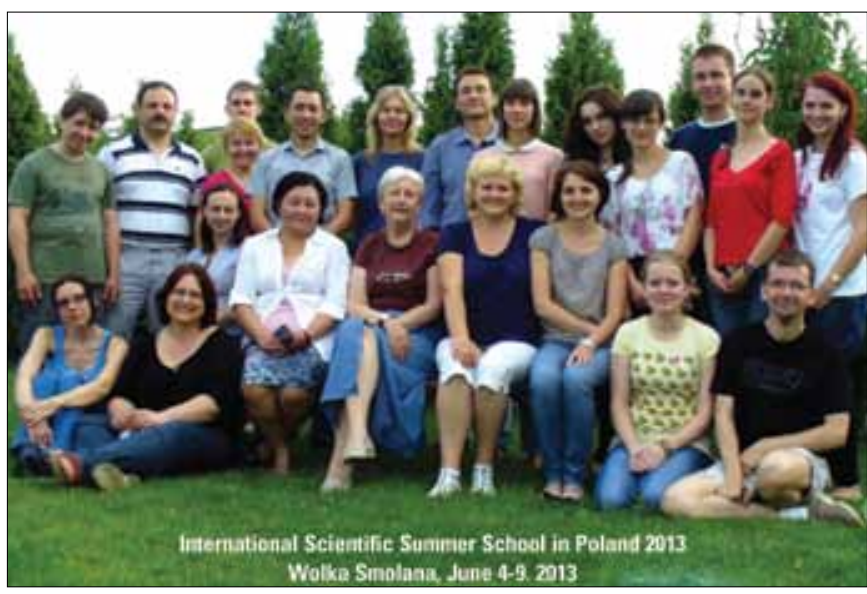

Figure 1. The International Scientific Summer School supported by the Balkan Medical Journal was held in June 2013 in Poland.

\section{Training of Authors}

Balkan Medical Journal has recently organized a structured programme for training authors. This programme, attended by all editors of Balkan Medical Journal, was held for the first time in the Central Library Halls of Trakya University on 30 May 2013. The meeting was announced one month in advance and twenty attendees registered. In the first session of the meeting, our editors gave lectures, while in the second session, a workshop was held. The lectures primarily tabled and discussed each component of standard scientific articles individually: title, abstract, selection of keywords suitable for $\mathrm{MeSH}$, introduction, materials and method, results, discussion, references, tables and figures were examined in detail during the session. In the final session, basic information on publication ethics, including duplication and plagiarism, were provided to the authors. The most common mistakes made in unapproved articles were addressed. Questions in the authors' minds were discussed and the most challenging issues were evaluated. All participants were reminded that our journal provides detailed information for authors, which is available on the website and in the print journal. In addition, it was mentioned that authors, reviewers and editors can find links to other useful websites through our site. A workshop was organized further in the process. Twenty participants were divided into four groups, with each group preparing a sample article. The participants presented their articles through PowerPoint presentations. At the end of the presentations, questions and comments were raised by both participants and editors (Figure 2).

Balkan Medical Journal plans to hold such events at least biannually. We aim to improve our website and reach young authors living in the Balkan countries in particular, drawing on the experience obtained through the training programs. Furthermore, we strive to minimize the technical questions on text flow by briefly informing the authors on the publication

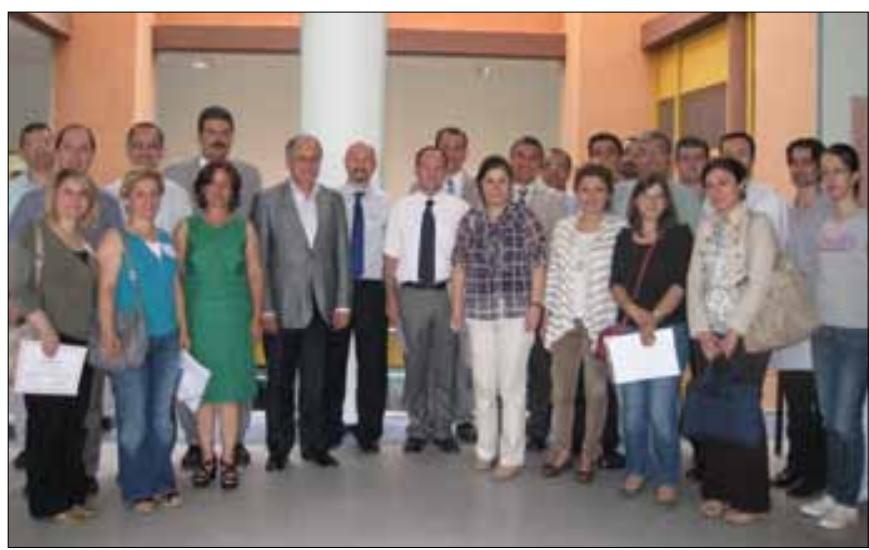

Figure 2. Training of authors programme, attended by all editors of Balkan Medical Journal, was held for the first time in the Central Library Halls of Trakya University on $\mathbf{3 0}$ May 2013

policy, scope, mission, editorial process, peer review, conflict of interest policy and understanding of ethics.

\section{Training of Reviewers and Information Sharing with Editors of Other Journals}

Thanks to the dazzling developments in information technology, we are witnessing revolutionary developments both in publishing and in publication ethics. Therefore, journal editors and reviewers must constantly refresh their knowledge and be aware of developments. As editors of the Balkan Medical Journal, we aim to be pioneers in the region, particularly in the realm of publication ethics. Therefore, we plan to organize a workshop in the spring of 2014 attended by prominent editors in this field from the region and around the world, to constitute a turning point in Turkey and in the Balkans as well as to raise awareness on plagiarism. Attendees will also include relevant experts from the Republic of Turkey Higher Education Institution, Turkish Science Academy and the other universities in the region. The meeting, if all goes well, will be in tandem with the ISSS and we will have the opportunity to exchange information with valuable scientists during the reviewer-editor workshop and the ISSS.

We would like to express our dedication to utilizing any and all means to uphold the active educational mission of our journal in the region. We intend to continue interactive communications with readers, researchers, authors, reviewers and editors of other journals in the near future. Our objective is to reflect the light of science produced in the Balkans, one of the oldest cradles of civilization, to the whole world.

Mustafa iNAN, MD

Section Editor of Surgical Sciences, Balkan Medical Journal

Department of Pediatric Surgery, Trakya University

Faculty of Medicine, Edirne, Turkey 